\title{
Experimental Evaluation of Metal Composite Multi Bolt Radial Joint on Laminate Level, under uni Axial Tensile Loading
}

\author{
C Sharada Prabhakar ${ }^{*}$, P Rameshbabu** \\ *Scientist, Advanced Systems Laboratory, Dr A. P. J. Abdul Kalam Missile Complex DRDO, Hyderabad, \\ Telangana, 500058, India \\ **Associate Professor, Department of Mechanical Engineering University College of Engineering, Osmania \\ University, Hyderabad, Telangana, 500007, India
}

\begin{abstract}
Longitudinal tensile load exerted due to internal hydraulic pressure, on bolted radial joints between large size PAN carbon epoxy filament wound composite cylindrical section and small size 15CDV6 steel cylindrical sections, were simulated and tested on flat laminate level, mainly to check the strength of PAN carbon epoxy helical wound laminate made by wet winding method. Small segmental portion of circumference of cylindrical sections was considered as width of composite laminate and of metallic plates, necessary to accommodate 5 rows of fasteners in transverse direction with specified pitch distance. Bolted radial joints between carbon epoxy helical wound flat laminate and 15CDV6 steel plates were realized with 8 numbers of steel fasteners distributed in 3 longitudinal and 5 transverse rows at each joint. Helical angle of winding, length and thickness of carbon epoxy laminate was $\pm 22.5^{\circ}, 458 \mathrm{~mm}$ and $11 \mathrm{~mm}$ respectively. Length and structural thickness of radial joints, total length and width of assembly test specimen were $98 \mathrm{~mm}, 18 \mathrm{~mm}, 870 \mathrm{~mm}$ and $169.43 \mathrm{~mm}$ respectively. Joints were tested under uni-axial tensile load up to failure. Joints failed at 18 tonnes (1.7 times of design load). Failure mode was observed as initiation of bearing failure at all 8, countersink fastener holes in laminate and shear out failure at edge hole. Strains in fibre direction, at $45^{\circ}$ and at transverse to fibre direction were found very less. Maximum compressive strain and residual strain, near fastener holes were found as -1423 and -136 micro strain respectively. Test was successful.
\end{abstract}

Key Words: 15CDV6 steel flat plates, PAN carbon epoxy helical wound flat laminate, multi bolt radial joint, uni-axial tensile load test and initiation of bearing failure in all 8 holes.

\section{INTRODUCTION}

Composite materials are widely used as structural materials because of high specific strength and specific stiffness. However to realize complete structural member, composites have to be joined with another composite or metallic section. These components can be joined with the help of adhesives or mechanical fasteners.

There was requirement to develop large size (app 10meters long, 800mm diameter and $18 \mathrm{~mm}$ thickness), bolted radial joint assembly of 15CDV6 steel cylindrical sections and PAN Carbon epoxy filament wound cylindrical section and to carry out internal hydraulic pressure testing of assembly. Small 15CDV6 steel cylindrical sections are proposed to be joined to large size PAN Carbon epoxy helical wound (by wet winding), cylindrical section (app 8mts long) on both ends, with the help of bolted radial joints. Fasteners are staggered in 3 longitudinal rows. Before developing hardware of large size metal composite cylindrical section's assembly and testing for internal hydraulic pressure, longitudinal tensile load exerted due to internal hydraulic pressure was simulated and tested on laminate level; to check the strength of PAN Carbon epoxy helical wound laminate. However hoop loads could not be simulated in laminate level test.

For laminate level testing, small segmental portion of circumference of cylindrical section was considered as width of flat composite laminate and of flat metallic plates, to accommodate 5 rows of fasteners in transverse direction with specified pitch distance. Sufficient length of composite laminate was considered to accommodate metal composite bolted radial joints on both ends with 8 number of fasteners (distributed in 3 longitudinal rows with specified pitch distance) on each end. Configuration of joint on both ends was same. Metal composite flat laminate assembly was subjected to uni axial tensile load till failure.

Aim of the experiment was to check the strength and failure modes of PAN carbon epoxy helical wound (by wet winding) flat composite laminate. In this experimental work, product development and experimental evaluation of metalcomposite multi bolt radial joint on flat laminate level under uni-axial tensile loading was considered. 
Details of fabrication of T300 PAN Carbon epoxy helical wound flat laminates by wet winding method, metallic plates, fasteners, metal composite multi bolt radial joint and testing of joints under uni-axial tensile load are presented in this paper.

\section{DETAILS OF METAL-COMPOSITE MULTI BOLT RADIAL JOINT ON LAMINATE LEVEL}

Metal composite multi bolt radial joint configuration on flat laminate level considered for uni-axial tensile load testing is shown in figure-1 (drawn not to scale).
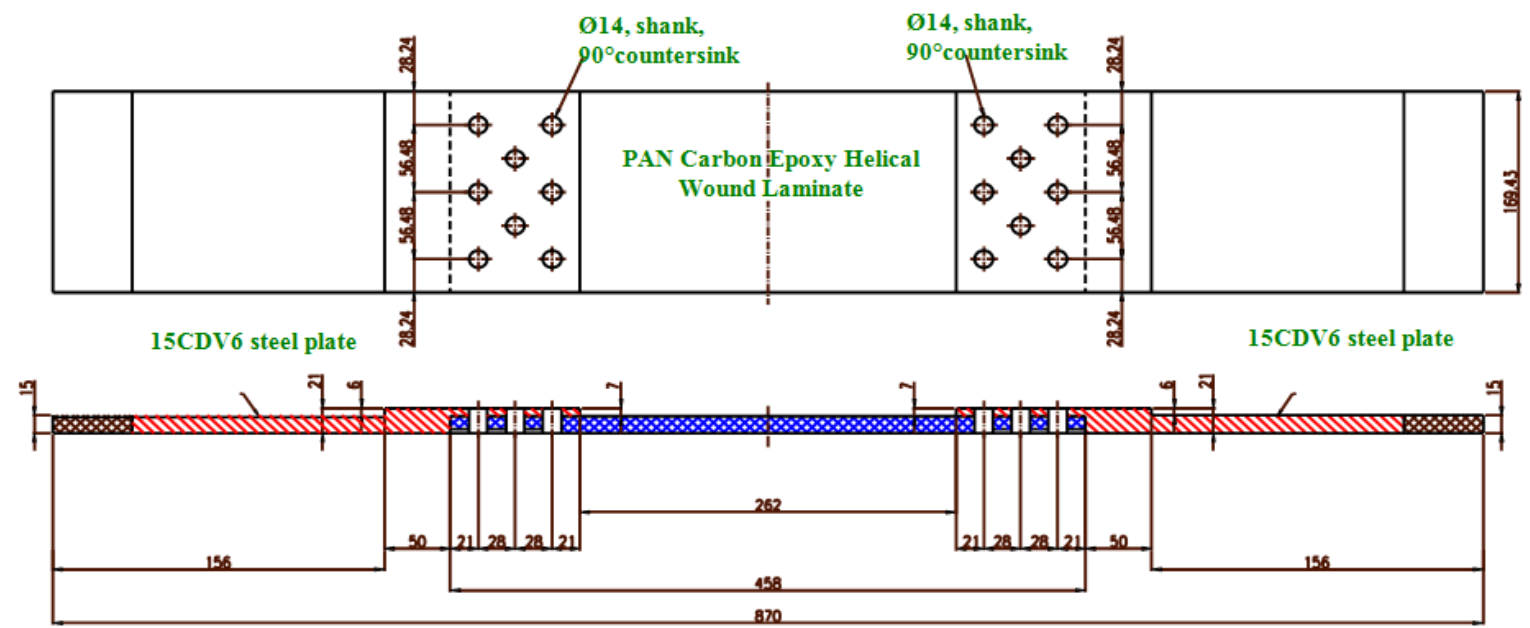

Fig.1. PAN Carbon epoxy-15CDV6 steel, multi bolt radial joint assembly on flat laminate level

Width of composite laminate and metallic plates, was considered as $169.43 \mathrm{~mm}$ and it was necessary to accommodate 5 rows of fasteners in transverse direction with required pitch distance. Length of composite laminate was considered as $458 \mathrm{~mm}$ and length of each metallic plates were considered as $304 \mathrm{~mm}$. Length of the joint on both ends was $98 \mathrm{~mm}$, required to accommodate 3 longitudinal rows of fasteners with required pitch distance and edge distance. Total length of metal composite multi bolt radial joint flat laminate assembly test specimen was $870 \mathrm{~mm}$. Total thickness of proposed metal composite bolted radial joint portion of cylindrical sections was considered as $21 \mathrm{~mm}$. Out of $21 \mathrm{~mm}, 18 \mathrm{~mm}$ was structural thickness and $3 \mathrm{~mm}$ thickness was provided for innermost thermal protection layer and leak proof layer. $18 \mathrm{~mm}$ structural thickness includes $11 \mathrm{~mm}$ PAN carbon epoxy laminate thickness and $7 \mathrm{~mm}$ metal thickness. Structural thickness at shell portion of proposed composite section was $15 \mathrm{~mm}$ ( $11 \mathrm{~mm}$ helical and $4 \mathrm{~mm}$ hoop). Hoop layers will not contribute in longitudinal load transfer and hence not considered for laminate level test. Only $11 \mathrm{~mm}$ of helical thickness was considered for laminate level test. Angle of winding for helical layers was $\pm 22.5^{\circ}$.

Joint design depends on fastener diameter, number of rows, thickness of metal and composite (helical layers), at the overlap region. Metal composite bolted radial joint on laminate level was realized with 8 number of fasteners. Following are the details of fasteners:
- Fasteners: Special screw and nut.

- Material of fasteners --EN24 10.9 property class.

- Diameter of holes in laminate and metallic plates $=14 \mathrm{~mm}$.

- Shank diameter of fastener $=14 \mathrm{~mm}$.

- Internal threads on nut=M6.

- External threads on screw=M6.

- Countersunk angle on nut and screw $=90^{\circ}$.

- Number of fasteners $=8$.

- Number of Rows of fasteners in longitudinal direction $=3$.

- Number of fasteners in $1^{\text {st }}$ and $3^{\text {rd }}$ row in longitudinal direction $=3$ (in similar way).

- Number of fasteners in $2^{\text {nd }}$ row in longitudinal direction $=2$.

- $\quad$ Longitudinal pitch distance $=28 \mathrm{~mm}$.

- Longitudinal edge distance $=21 \mathrm{~mm}$.

- $\quad$ Transverse pitch distance $=28.24 \mathrm{~mm}$.

- Transverse edge distance of fasteners = $28.24 \mathrm{~mm}$.

\section{MANUFACTURING OF METAL- COMPOSITE MULTI BOLT RADIAL JOINT ASSEMBLY TEST SPECIMEN}

3.1 PAN Carbon epoxy Helical Wound Laminate

Apart from design, composite product development (by wet winding/lay-up) is very critical, especially for filament wound polymeric composites. Quality of filament wound polymeric 
composites is highly process oriented. Component is made layer by layer.

PAN carbon epoxy helical wound, flat, thick laminate was wound with very low angle of winding to reduce mismatch of axial extension of metallic plate and composite laminate between two adjacent rows of fasteners. Lower angle of winding will give more longitudinal stiffness, resulting in reduced mismatch in longitudinal extension of metallic plate and composite laminate between two adjacent rows of fasteners. Moreover lower angle of winding will have more strength in axial direction and hence more load transfer at the joint. Generally Uni-directional and Bi-directional flat, thin ( 2 to $3 \mathrm{~mm}$ thickness) composite laminates are made for characterization of mechanical properties of composite materials. Making multi-angle, thick, flat laminates by wet filament winding technology is critical process.

Carbon epoxy thick, flat laminates were developed by wet helical winding method, with low helical angle of winding as $\pm 22.5^{\circ}$. Metallic cylindrical mandrel with hemispherical end domes was used for helical winding. CNC program for helical winding with $\pm 22.5^{\circ}$ as angle of helical winding, was generated and one helical layer of $1.5 \mathrm{~mm}$ thickness, with PAN carbon epoxy was wet wound. Schematic of mandrel, loaded on CNC Filament winding machine is shown in figure-2.

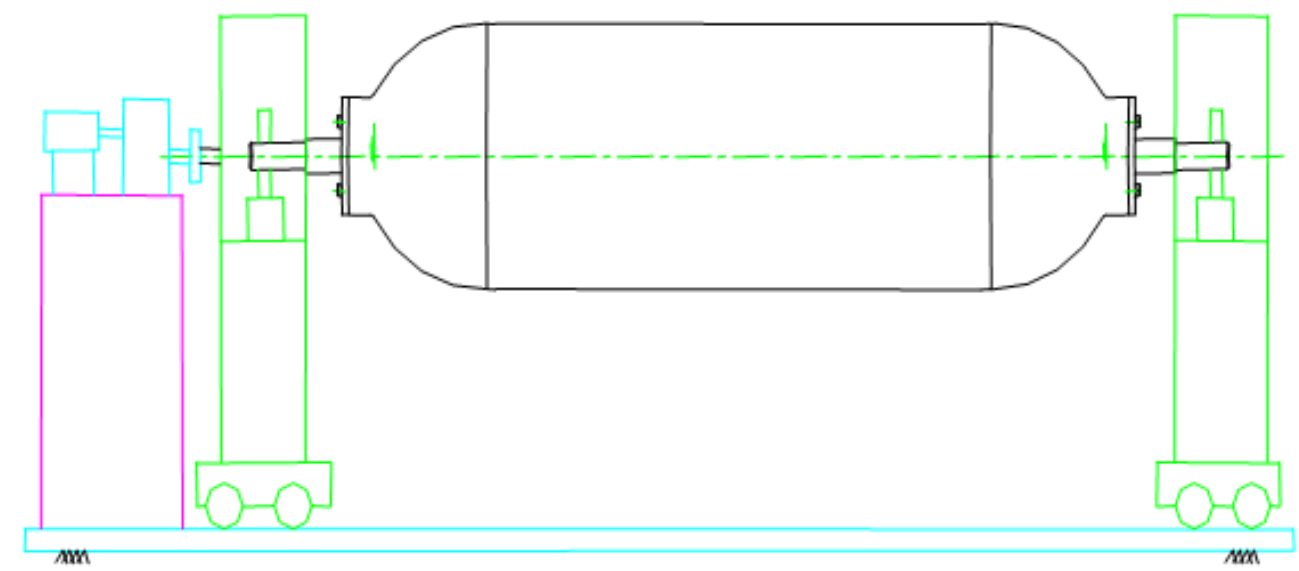

Fig.2. Mandrel loaded on CNC Filament Winding machine

After winding, 8 pieces were cut in wet condition and stacked on flat metallic mould, closed with top plate and spacers and laminate was cured in hydraulic press at $140^{\circ} \mathrm{C}$ for 4 hours, under 15 tons hydraulic load. 2 laminates of $400 \times 500$ x $12 \mathrm{~mm}$ were made. Cured laminates were machined to required dimensions.

Resin content and density were checked on samples taken from extra length of composite laminate. Resin content was measured as $\mathbf{4 4 . 2 1 \%}$. Volume fraction achieved in test laminate is found much less than $\mathbf{6 0 \%}$. Average density was measured as $\mathbf{1 . 4 1 g m / c c}$. Ultrasonic test was carried out to check the defects, if any. Defects were with in specified limit.

Carbon fibres with epoxy compatible sizing were used for wet filament winding process but wetting of carbon fibre with epoxy resin was observed poor. More resin was deposited on surface of fibre (in between layers). Laminates were resulted with more resin content.

\subsection{CDV6 Metallic plates}

15CDV6 steel forged plates were ultrasonically tested, rough machined, heat treated. Established heat treatment cycle for grain refinement, hardening and tempering was followed. Milling of plates to required dimensions and drilling of holes for gripping were carried out. Length of 15CDV6 Metallic plates was 304mm.

\subsection{Metallic fasteners}

Special screws and nuts were machined from EN24 Steel alloy, hot rolled and heat treated rod. Fasteners of 10.9 property class were used. These fasteners were cadmium plated and inspected for dimensions and mechanical properties. Duly accepted fasteners were used for joint. Drawing of special screw and photograph of special nut are shown in figure- 3 and figure- 4 . 


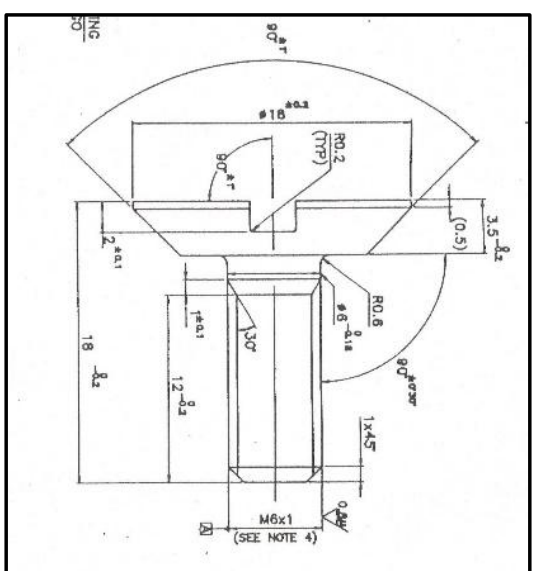

Fig.3. Special screw

\subsection{Drilling of Countersunk holes for metal composite multi bolt radial joint}

Realization of metal composite multi bolt radial joint is critical process. For realizing mechanical fastening, holes have to be drilled on composite laminates which will generate high stress concentration zones near holes. Many defects may be induced in the laminates, during drilling. Hence during drilling, proper cutting tools and cutting parameters have to be selected. During drilling of radial holes on composites, proper back up has to be placed beneath the composite laminate. Solid carbide drills were used during

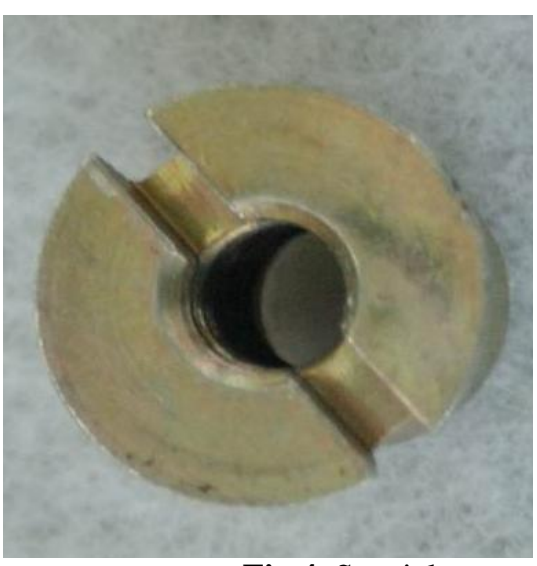

Fig.4. Special nut

drilling and drilling of $14 \mathrm{~mm}$ diameter holes were drilled in many stages.

$14 \mathrm{~mm}$ diameter straight holes with $90^{\circ}$ countersunk on top surface (18mm diameter), 8 numbers were drilled on 15CDV6 plates (in three rows: -3 holes in $1^{\text {st }}$ and $3^{\text {rd }}$ row, 2 holes in $2^{\text {nd }}$ row). For drilling of $14 \mathrm{~mm}$ diameter holes on composite test laminate specimens, centre of hole was transferred from metallic plates and holes were drilled with $90^{\circ}$ countersunk (18mm diameter) on top surface of laminate. Composite test laminate specimen was having metal back up during drilling. PAN carbon epoxy composite laminate, after drilling is shown in figure-5.

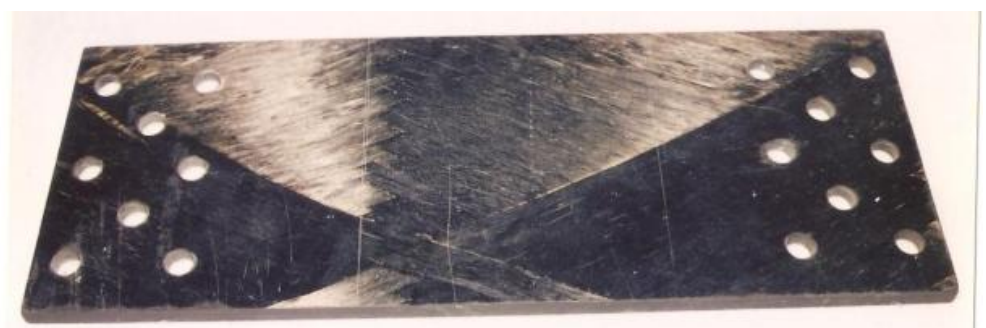

Fig.5. Drilling of holes on composite laminate

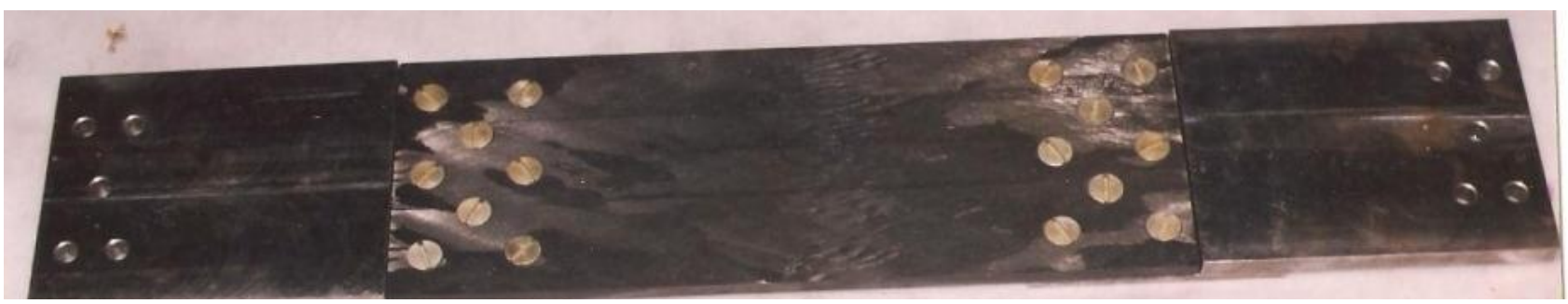

Fig.6. Metal composite multi bolt radial joint assembly test specimen

\subsection{Assembly of metallic plates and composite} laminate

Metallic plates and carbon-epoxy composite test laminate specimen were assembled with M6 special screws and nuts with $14 \mathrm{~mm}$ shank diameter. Thus metal composite laminate test specimen was made ready for test. Assembly of metal composite multi bolt radial joint assembly test specimen is shown in figure-6. Enlarged view of joint is shown in figure- 7 . 


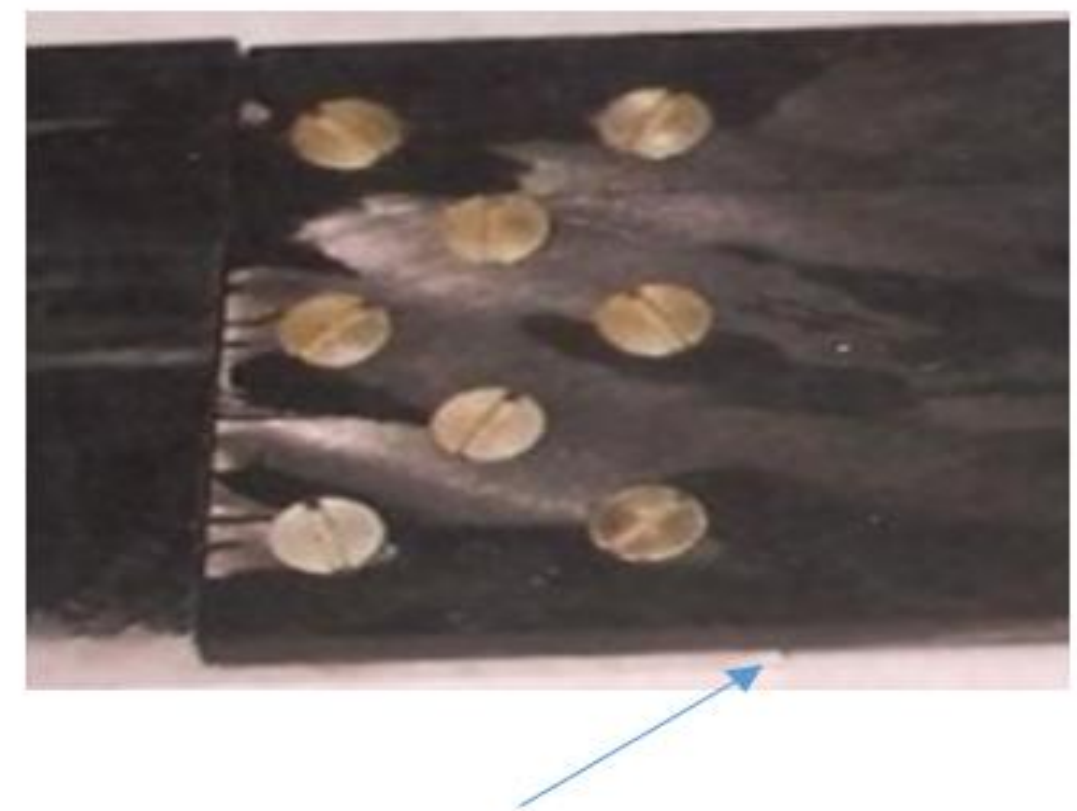

Fig.7. Enlarged view of metal composite multi bolt radial joint, to show overlap region on metallic plate

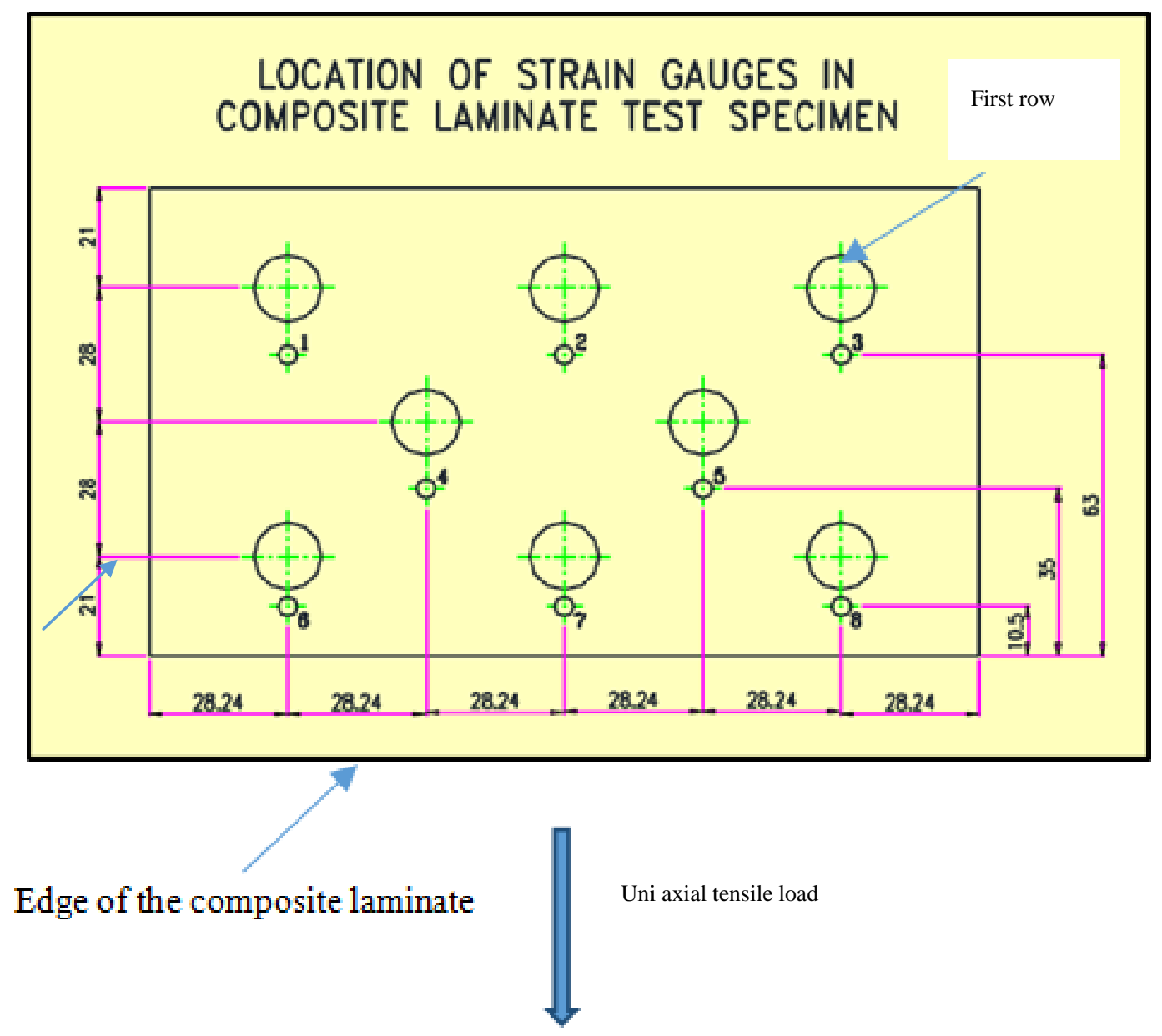

Fig.8. Location of strain gauges in composite laminate 


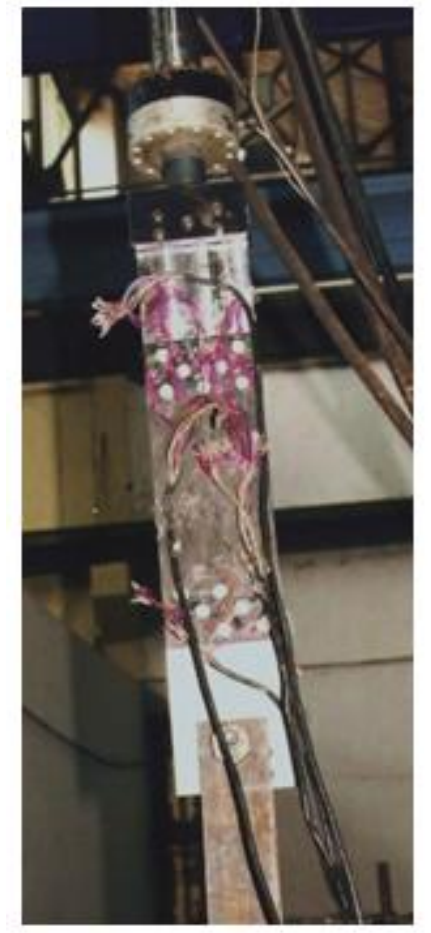

Fig.9. Test set up with test specimen

Strain gauges were placed near each fastener hole, in the PAN carbon epoxy helical wound laminate, to measure crushing or bearing failure of loaded (contact region) portion of holes as well as strains in stress concentration zone. Location of strain gauges near each fastener hole in composite laminate test specimen is shown in figure-8. Strain gauges in $1^{\text {st }}$ row (farthest from edge of laminate) are located at $63 \mathrm{~mm}$ from the edge of the laminate. Strain gauges in middle row are located at $35 \mathrm{~mm}$ from the edge of the laminate and strain gauges in $3^{\text {rd }}$ row (last) are located at $10.5 \mathrm{~mm}$ from the edge of the laminate. Location of strain gauges in $1^{\text {st }}$ and $2^{\text {nd }}$ row is $7 \mathrm{~mm}$ from the edge of the respective fastener holes. Location of strain gauges in the $3^{\text {rd }}$ row is $3.5 \mathrm{~mm}$ from the edge of the fastener holes.

\section{EXPERIMENT}

Experimental investigation of metalcomposite multi bolt radial joint between PAN Carbon epoxy helical wound flat, thick laminate and 15CDV6 plates was carried out. Failure in composite laminate and failure of joint was found out experimentally.

Design load for uni-axial tensile load test $=10.58$ tons

Ultimate load=15.87 tons ( $1.5 \mathrm{x}$ design load $)$.
Strains and displacements were measured during test. Test set up with test specimen for experiment is shown in figure-9.

Test specimen is loaded up to $10 \mathrm{~T}$ of tensile load in steps of 1T. At each discrete loading, strain and deflection values were recorded. Load was brought back to 0 . Residual strains were also recorded.

After that, test specimen was loaded continuously up to $18 \mathrm{~T}$ (to the capacity of loading device). At $18 \mathrm{~T}$ load there was no visual failure observed in the test laminate and at the joint portion. Expected failure load was also 18 tons.

Metal composite laminate multi bolt radial joint assembly was dis-assembled for inspection.

\section{RESULTS AND DISCUSSIONS}

- In the composite laminate test specimen, at all holes, initiation of bearing failure was observed. At end hole of end row $\left(8^{\text {th }}\right.$ strain gauge), shear out failure was also initiated. Edge distance, 1.5D is maintained. Shear out failure can occur because of low transverse tensile strength and shear strength also.

- Laminate test specimen was made by helical wet winding. Control of resin content during wet winding, is very difficult. Resin content was found more in laminates which means laminate is having less volume fraction. With low helical winding $\left( \pm 22.5^{\circ}\right)$, transverse tensile strength of laminate will be less. Testing of mechanical properties with same material also has resulted in lower values. Transverse tensile strength test value was found only $27.5 \mathrm{MPa}$. To control the resin content, towpreg can be used for helical winding. Quality of laminates also can be improved and further factor of safety on joint can be improved, however $\mathbf{1 . 7}$ factor of safety was achieved on joint.

- At 10T of load net deflection was $1.90 \mathrm{~mm}$ and max strain value was $\mathbf{3 2 3 4}$ micro strain near hole of fastener no. 4 in middle row. Maximum compressive strain in contact region was observed as $\mathbf{- 1 4 2 3}$ micro strain near hole of fastener no. 7 in last row.

- Max residual strain measured was -136 micro strain. It was compressive strain.

- Ultimate strain of PAN Carbon (T300) epoxy of the laminate is app 13000 micro-strain.

- Countersink hole side, straight hole (14mm) side and enlarged view of straight hole side of laminate test specimen, after test are shown in figure-10, figure-11 and figure-12 respectively.

- Compressive strain values in contact region of holes up to 10 tons of load and residual strain were found very less in all holes of fasteners. 


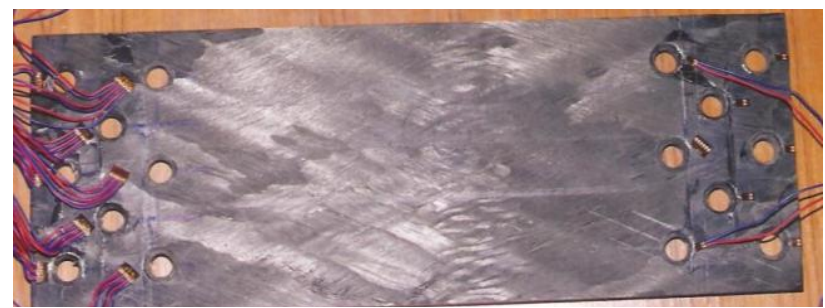

Fig.10. Countersink hole side of laminate test specimen, after test

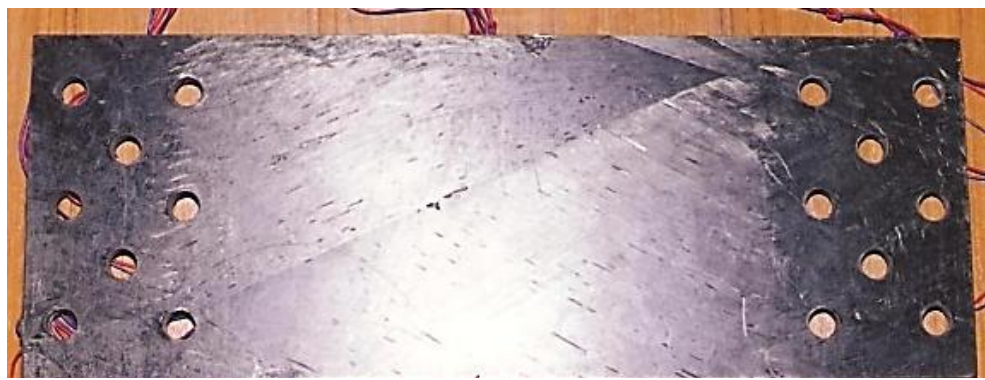

Fig.11. Strainght hole side $(14 \mathrm{~mm})$ of laminate test specimen, after test

\subsection{Strain data}

Strain were recorded near all 8 fastener holes, in fibre direction, at $45^{\circ}$ and transverse to fibre direction, at every 1 ton of loading, up to 10 tons loading. Strain at strain gauge-1, strain gauge2 and strain gauge-3, for all loadings and residual strain values at these strain gauges are given in table-1. Strain at strain gauge-4 and strain gauge-5 for all loadings and residual strain values at these strain gauges are given in table-2. Strain at strain gauge-6, strain gauge-7 and strain gauge- 8 , for all loadings and residual strain values at these strain gauges are given in table-3. Strain plots at fibre direction in all 8 strain gauges are shown in figure13. Maximum strain in fibre direction, is recorded as $\mathbf{- 1 2 8 5}$ micro strain near fastener hole-6, at $3^{\text {rd }}$ (end) row.

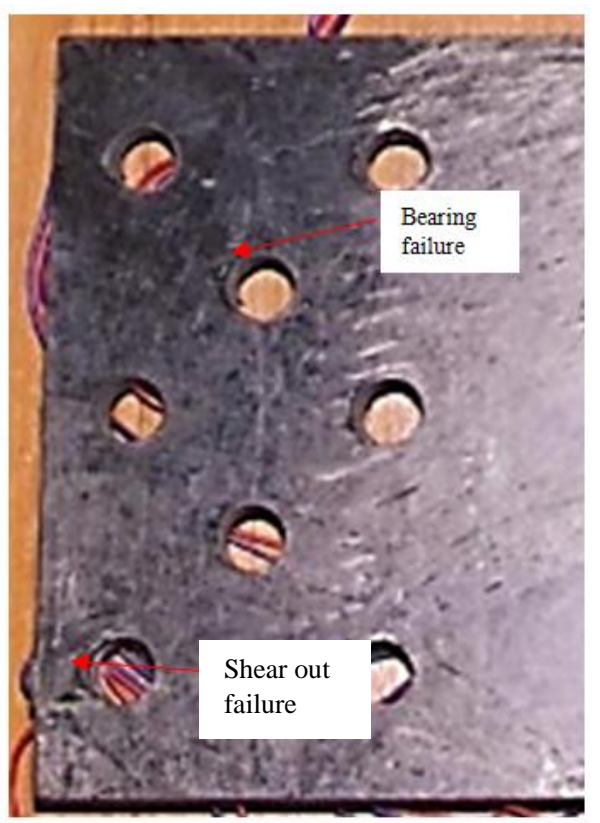

Fig.12. Enlarged view of straight hole side $(14 \mathrm{~mm})$ of laminate test specimen, after test

5.1.1Strain, near fastener holes in laminate, at the farthest distance from edge- $1^{\text {st }}$ row $\left(1^{\text {st }}, 2^{\text {nd }}\right.$ and $3^{\text {rd }}$ fastener holes)
Strain in Strain gauge-1, Strain gauge-2 and Strain gauge-3 (near $1^{\text {st }}, 2^{\text {nd }}$ and $3^{\text {rd }}$ fastener holes respectively)

Strain were measured in fibre direction, at $45^{\circ}$ and in transverse to fibre direction. Measured strains in 
all 3 directions at strain gauges 1,2 and 3 are shown in Table-1.

Table-1: Strain, near Fastener holes in Laminate at Farthest distance from edge- $1^{\text {st }}$ Row $\left(1^{\text {st }}, 2^{\text {nd }} \& 3^{\text {rd }}\right.$ fastener holes)

\begin{tabular}{|c|c|c|c|c|c|c|c|c|c|}
\hline \multirow{2}{*}{$\begin{array}{l}\text { Koad in } \\
\text { Kgs }\end{array}$} & \multicolumn{3}{|c|}{$\begin{array}{l}\text { Strain, near fastener hole, } \\
\text { in fibre direction }\end{array}$} & \multicolumn{3}{l|}{$\begin{array}{l}\text { Strain, near fastener hole, } \\
\text { at 45 }\end{array}$} & \multicolumn{3}{l|}{$\begin{array}{l}\text { Strain, near fastener hole, in } \\
\text { transverse to fibre direction }\end{array}$} \\
\cline { 2 - 10 } & Hole-1 & Hole-2 & Hole-3 & Hole -1 & Hole -2 & Hole-3 & Hole -1 & \multicolumn{1}{l|}{ Hole -2 } & Hole -3 \\
\hline 0 & 0 & 0 & 0 & 0 & 0 & 0 & 0 & 0 & 0 \\
\hline 1000 & -92 & -86 & -94 & -66 & -76 & -70 & -28 & -38 & -17 \\
\hline 2000 & -182 & -166 & -185 & -84 & -146 & -139 & -61 & -75 & -59 \\
\hline 3000 & -267 & -233 & -283 & -131 & -219 & -206 & -94 & -105 & -103 \\
\hline 4000 & -362 & -311 & -390 & -161 & -296 & -280 & -128 & -134 & -126 \\
\hline 5000 & -456 & -424 & -470 & -307 & -373 & -350 & -150 & -165 & -170 \\
\hline 6000 & -503 & -499 & -560 & -382 & -436 & -410 & -183 & -196 & -202 \\
\hline 7000 & -572 & -586 & -653 & -451 & -509 & -482 & -219 & -231 & -226 \\
\hline 8000 & -657 & -666 & -745 & -512 & -576 & -560 & -249 & -275 & -259 \\
\hline 9000 & -719 & -726 & -839 & -627 & -649 & -639 & -288 & -314 & -302 \\
\hline 10000 & -779 & -811 & -930 & -675 & -720 & -710 & -330 & -342 & -328 \\
\hline $\begin{array}{c}\text { Residual } \\
\text { Strain }\end{array}$ & -37 & -37 & -60 & -136 & -27 & -16 & -24 & -39 & -14 \\
\hline
\end{tabular}

5.1.2 Strain, near fastener holes in laminate at the Middle row- $2^{\text {nd }}$ row ( $4^{\text {th }}$ and $5^{\text {th }}$ fastener holes) Strain in Strain gauge-4 and Strain gauge-5 (near $4^{\text {th }}$ and $5^{\text {th }}$ fastener holes respectively)

Strain were measured in fibre direction, at $45^{\circ}$ and in transverse to fibre direction. Measured strains in all 3 directions at strain gauges 4 and 5 are shown in Table-2.

Table-2: Strain, near Fastener holes in Laminate at Middle Row $-2^{\text {nd }}$ row $\left(4^{\text {th }} \& 5^{\text {th }}\right.$ fastener holes $)$

\begin{tabular}{|c|c|c|c|c|c|c|}
\hline \multirow{2}{*}{$\begin{array}{l}\text { Koads in } \\
\text { Kgs }\end{array}$} & \multicolumn{2}{l|}{$\begin{array}{l}\text { Strain in fibre direction, } \\
\text { near fastener hole }\end{array}$} & \multicolumn{2}{l|}{$\begin{array}{l}\text { Strain at } \mathbf{4 5}^{\circ} \text {, near } \\
\text { fastener hole }\end{array}$} & \multicolumn{2}{l|}{$\begin{array}{l}\text { Strain in transverse to fibre } \\
\text { direction, near fastener hole }\end{array}$} \\
\cline { 2 - 7 } & Hole-4 & Hole-5 & Hole-4 & Hole-5 & Hole-4 & Hole-5 \\
\hline 0 & 0 & 0 & 0 & 0 & 0 & 0 \\
\hline 1000 & -135 & -114 & 159 & -95 & 200 & 156 \\
\hline 2000 & -196 & -282 & 245 & -37 & 389 & 312 \\
\hline 3000 & -262 & -397 & 335 & 82 & 593 & 467 \\
\hline 4000 & -356 & -509 & 490 & 199 & 974 & 723 \\
\hline 5000 & -446 & -602 & 642 & 292 & 1355 & 980 \\
\hline 6000 & -528 & -702 & 793 & 345 & 1742 & 1175 \\
\hline 7000 & -628 & -816 & 944 & 425 & 2130 & 1432 \\
\hline 8000 & -728 & -939 & 1091 & 493 & 2442 & 1765 \\
\hline 9000 & -897 & -1162 & 1298 & 622 & 2998 & 2013 \\
\hline 10000 & -955 & -1244 & 1382 & 670 & $\mathbf{3 2 3 4}$ & 2369 \\
\hline $\begin{array}{c}\text { Residual } \\
\text { Strain }\end{array}$ & -66 & -61 & 77 & 102 & 10 & 58 \\
\hline
\end{tabular}

5.1.3 Strain, near fastener holes in laminate at the end row $-3^{\text {rd }}$ row, $\left(6^{\text {th }}\right.$, 7th and $8^{\text {th }}$ fastener holes) Strain in Strain gauge-6, Strain gauge-7 and Strain gauge-8 (near $6^{\text {th }}, 7^{\text {th }}$ and $8^{\text {th }}$ fastener holes respectively) Strain were measured in fibre direction, at $45^{\circ}$ and in transverse to fibre direction. Measured strains in all 3 directions at strain gauges 6,7 and 8 are shown in Table-3.

Table-3: Strain, near fastener holes in laminate at the end row- $3^{\text {rd }}$ row $\left(6^{\text {th }}, 7^{\text {th }}\right.$, and $8^{\text {th }}$ fastener holes $)$

\begin{tabular}{|c|c|c|c|c|c|c|c|c|c|}
\hline \multirow[t]{2}{*}{$\begin{array}{l}\text { Loads } \\
\text { in Kgs }\end{array}$} & \multicolumn{3}{|c|}{$\begin{array}{l}\text { Strain in Fibre Direction near } \\
\text { fasteners Hole }\end{array}$} & \multicolumn{3}{|c|}{ Strain at $45^{\circ}$, near fasteners hole } & \multicolumn{3}{|c|}{$\begin{array}{l}\text { Strain in transverse to fibre } \\
\text { direction }\end{array}$} \\
\hline & $\begin{array}{l}\text { Fastener } \\
-6\end{array}$ & $\begin{array}{l}\text { Fastener } \\
-7\end{array}$ & $\begin{array}{l}\text { Fastener } \\
-8\end{array}$ & $\begin{array}{l}\text { Fastener } \\
-6\end{array}$ & $\begin{array}{l}\text { Fastener } \\
-7\end{array}$ & $\begin{array}{l}\text { Fastener } \\
-8\end{array}$ & $\begin{array}{l}\text { Fastener } \\
-6\end{array}$ & $\begin{array}{l}\text { Fastener } \\
-7\end{array}$ & $\begin{array}{l}\text { Fastener } \\
-8\end{array}$ \\
\hline 0 & 0 & 0 & 0 & 0 & 0 & 0 & 0 & 0 & 0 \\
\hline 1000 & -123 & -132 & -102 & -56 & -142 & -96 & -42 & -28 & -34 \\
\hline 2000 & -198 & -211 & -198 & -124 & -235 & -180 & -75 & $\begin{array}{l}-67 \\
\end{array}$ & -86 \\
\hline 3000 & -290 & -289 & -276 & -205 & -390 & -285 & -105 & -125 & -126 \\
\hline 4000 & -395 & -365 & -417 & -290 & -446 & -370 & -134 & -184 & -179 \\
\hline
\end{tabular}




\begin{tabular}{|c|c|c|c|c|c|c|c|c|c|}
\hline 5000 & -511 & -474 & -526 & -387 & -590 & -489 & -165 & -212 & -235 \\
\hline 6000 & -615 & -580 & -718 & -467 & -727 & -583 & -196 & -238 & -289 \\
\hline 7000 & -824 & -701 & -802 & -523 & -912 & -690 & -231 & -295 & -390 \\
\hline 8000 & -953 & -812 & -889 & -615 & -1135 & -794 & -275 & -365 & -486 \\
\hline 9000 & -1102 & -934 & -990 & -703 & -1296 & -910 & -314 & -435 & -612 \\
\hline 10000 & -1285 & -1116 & -1107 & -798 & $-\mathbf{1 4 2 3}$ & -1002 & -342 & -510 & -815 \\
\hline $\begin{array}{c}\text { Residual } \\
\text { Strain }\end{array}$ & -34 & -12 & -29 & -14 & -76 & -45 & -39 & -12 & -22 \\
\hline
\end{tabular}

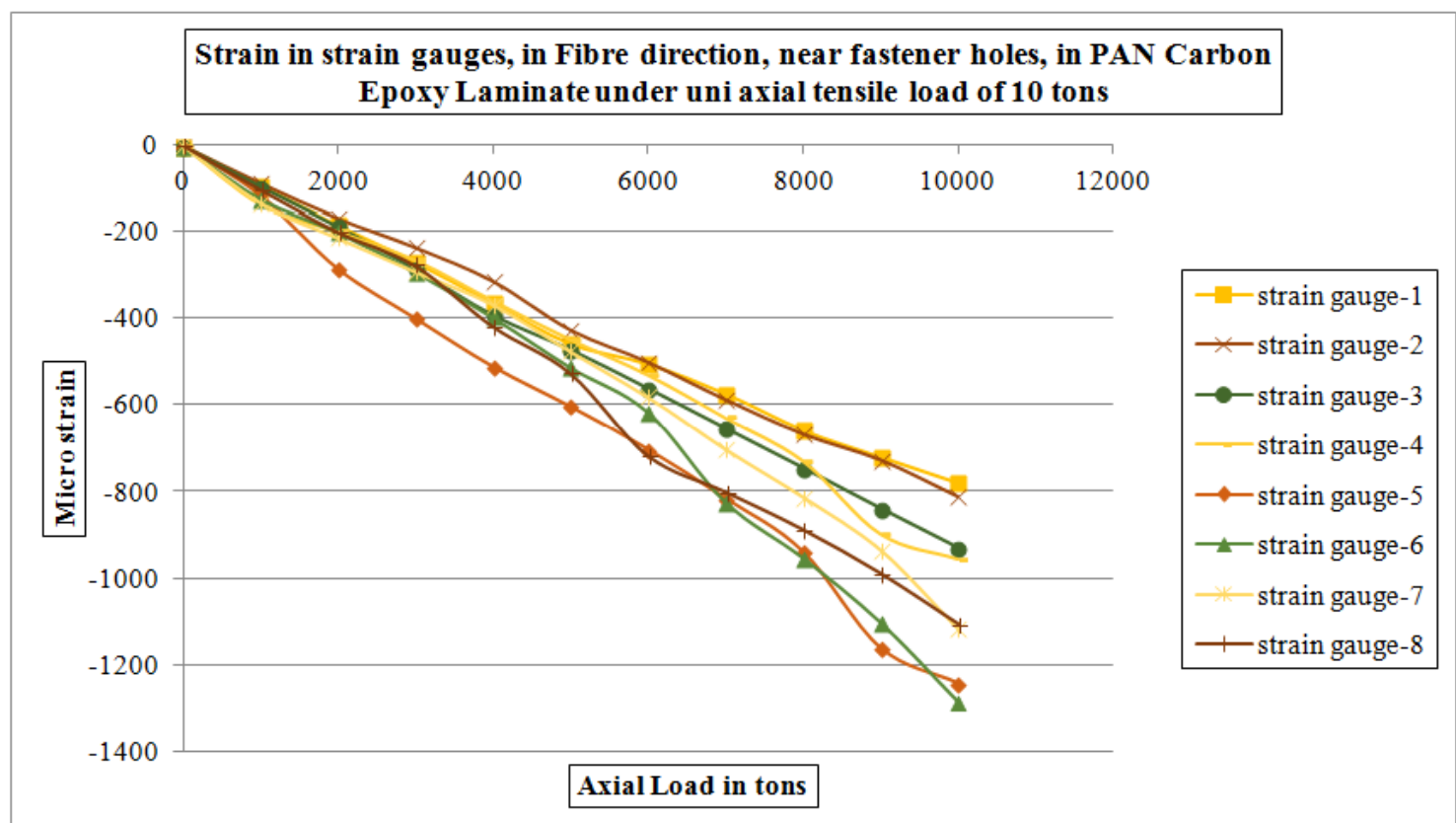

Fig.13. Strain plots at fibre direction in all 8 strain gauges

\section{CONCLUSION}

Multi bolt radial joint between PAN Carbon epoxy wet helical wound flat laminate and 15CDV6 steel flat plates, under uni-axial tensile loading is evaluated. In this experiment, two metallic flat plates were joined to one composite laminate at both the ends. Both metallic plates with adapters were held in testing machine during testing. Assembly could be tested up to 18 tons, (limitation of loading facility). At 18 tons, there was no visual failure seen. Hence after test, composite laminate was dis assembled. No failure was observed in metallic plates and fasteners. Bearing failure had initiated in all 8 fastener holes and shear out failure also had initiated in edge hole of last $\left(3^{\text {rd }}\right)$ row. Further assembly was not tested. At this load, failure had initiated in composite laminate test specimen.

Failure load observed was 18 tons. Failure was initiated by bearing and shear out failure in composite laminate at joint portion at 1.7 times of design load.

Quality of laminates can be further improved, if resin content is controlled during winding. Towpreg winding can give better results than that of wet winding, because, in towpreg, resin will be in controlled quantity and resin distribution also will be uniform in wound laminate and further factor of safety on joint can be improved, however 1.7 factor of safety, on design load was achieved on joint. Test was successful.

\section{ACKNOWLEDGEMENT}

Authors are extremely thankful to Associate director and Director of ASL for allowing to carry out this developmental work. They are extremely thankful to NDT group and structural testing group of DRDL/ASL for their support in carrying out tests. 